\title{
Identification of petroleum acids in Liaohe super-heavy oil
}

\author{
WU Bencheng and ZHU Jianhua* \\ School of Chemical Science and Engineering, China University of Petroleum, Beijing 102249, China
}

\begin{abstract}
In this study, petroleum acids were extracted from the super-heavy oil of Liaohe oilfield, North-east China, by using acetic acid, and their structural components and properties were investigated by using FT-IR and MS. Moreover, the trace metal contents in the super-heavy oil sample before and after acetic acid treatment were also measured in this work. The results showed that naphthenic acids were the main component of petroleum acids in Liaohe super-heavy oil, and the content of naphthenic acids with double rings was higher than that of other naphthenic acids. It can be concluded that petroleum acids in Liaohe super-heavy oil mainly consist of naphthenic acids, with a carbon number of around 11-69 and containing one to six naphthenic rings and/or one to two aromatic rings, and mainly exists in form of metal salts of petroleum acid. The molecular weight of petroleum acids is in the range of 190-1000.
\end{abstract}

Key words: Super-heavy oil, petroleum acids, extraction, trace metals, characterization

\section{Introduction}

Naphthenic acids and other organic acids in crude oil are usually called petroleum acids. Although the amount of petroleum acids is usually small, they may induce serious corrosion of metallic equipments and pipelines. Meanwhile, petroleum acids are important chemicals, and significant for petroleum geochemistry. Among petroleum acids, more than $85 \%$ are naphthenic acids. With strong acidity, and the reactions of amidation, esterification and neutralization, the naphthenic acids, a few aliphatic acids and dicarboxylic acids in crude oil can cause serious corrosion of metal. Apart from petroleum acids, the other compounds, such as phenol and mercaptan, also exist in crude oil, but they have lower acidity and would cause less corrosion.

In view of their corrosivity and commercial value, petroleum acids attract many researchers and the techniques for removal and separation of petroleum acids from crude oil or distillates have been developed worldwide. These include chemical methods, such as catalytic hydrogenation (Grande and Sorlie, 2000), alkaline neutralization (Varadaraj and David, 2000) and thermal decomposition (Blum et al, 1998), and physical methods, such as adsorption separation (Gaikar and Maiti, 1996). With more rigorous environmental protection standards, the technique for removal of petroleum acids is required to be clean, highly efficient and low in energy consumption.

The naphthenic acid structure can be determined by using mass spectrometry (MS) with different ionization methods such as electron ionization (EI) (John et al, 1998), chemical ionization (CI) (Dzidic et al, 1988), fast atom bombardment (FAB) (Gallegos, 1987), atmospheric pressure

*Corresponding author. email: rdcas@cup.edu.cn

Received October 17, 2008 chemical ionization (APCI) (Hsu et al, 2000) and electrospray ionization (ESI) (Qian et al, 2001; Barrow et al, 2003; Hughey et al, 2007; Gabryelski and Froese, 2003; Huang et al, 2007; Fu et al, 2007).

Our previous research results (Wu et al, 2006) demonstrated that the acid value of Liaohe super-heavy oil was higher than that of conventional crude oil. And most of the oil-soluble trace metals, such as calcium and manganese, exist in the form of metal salts of petroleum acid. Therefore, it is very necessary to analyze and determine the composition and structure of petroleum acids in this super-heavy oil.

In this work, the petroleum acids were separated from Liaohe super-heavy oil by solvent extraction, and their structures were characterized by Fourier-transform infrared (FT-IR) spectroscopy and electrospray ionization mass spectrometry (ESI-MS). The research results could be significant for the development of new deacidification techniques and the processing of super-heavy oil.

\section{Experimental methods}

\subsection{Analysis method for the properties of super- heavy oi1}

The super-heavy oil sample was supplied by the Liaohe Petrochemical Branch Company, PetroChina. According to the classification standard of crude oil, the Liaohe superheavy oil was classified into low-sulfur naphthenic crude oil. Based on the China standard GB 2540-81 (Petroleum products-Determination of density-Pycnometer method), the density of the sample was determined with a pycnometer. The viscosity of sample was measured according to ASTM 2196-99 (Standard test method for rheological properties of non-Newtonian materials by rotational viscometer) with an HADV II + rotational viscometer made by the Brookfield 
company, USA. The kind and content of trace metals in oil sample were measured with a Vista AX ICP-AES made by the Varian company, USA, according to ASTM 4951-02 (Standard test method for determination of additive elements in lubricating oils by inductively coupled plasma atomic emission spectrometry). The physical properties of the superheavy oil are listed in Table 1.

Table 1 Properties of Liaohe super-heavy oil sample

\begin{tabular}{|c|c|}
\hline Item & Data \\
\hline$\rho_{20}, \mathrm{~g} \cdot \mathrm{cm}^{-3}$ & 1.0003 \\
\hline$\eta_{50}, \mathrm{~Pa} \cdot \mathrm{s}$ & 158 \\
\hline Water, wt $\%$ & 2.34 \\
\hline Ash, wt $\%$ & 0.21 \\
\hline Salt, $\mathrm{mg} \cdot \mathrm{L}^{-1}$ & 9.4 \\
\hline Total acid number, $\mathrm{mg}(\mathrm{KOH}) \cdot \mathrm{g}^{-1}$ & 12.76 \\
\hline Initial boil point, $\mathrm{K}$ & 441 \\
\hline $\mathrm{C}, \mathrm{wt} \%$ & 84.71 \\
\hline $\mathrm{H}, \mathrm{wt} \%$ & 10.95 \\
\hline $\mathrm{S}, \mathrm{wt} \%$ & 0.45 \\
\hline $\mathrm{N}, \mathrm{wt} \%$ & 0.59 \\
\hline $\mathrm{O}, \mathrm{wt} \%$ & 2.20 \\
\hline $\mathrm{Ca}, \mu \mathrm{g} \cdot \mathrm{g}^{-1}$ & 524 \\
\hline $\mathrm{Ni}, \mu \mathrm{g} \cdot \mathrm{g}^{-1}$ & 125 \\
\hline $\mathrm{Fe}, \mu \mathrm{g} \cdot \mathrm{g}^{-1}$ & 47.5 \\
\hline $\mathrm{Mn}, \mu \mathrm{g} \cdot \mathrm{g}^{-1}$ & 17.4 \\
\hline $\mathrm{V}, \mu \mathrm{g} \cdot \mathrm{g}^{-1}$ & 2.1 \\
\hline
\end{tabular}

\subsection{Separation and purification of petroleum acids}

Petroleum acids can be separated from crude oil or distillates by many methods. In this work the solvent extraction method was used. At first, the super-heavy oil was acidified in order to recover the petroleum acids from their metal salts. The petroleum acids were then separated from the oil phase by means of alcohol-alkali extraction. The detailed procedures are as follows:

(1) A 20g super-heavy oil sample was added into an erlenmeyer flask, and diluted with $140 \mathrm{~g}$ cyclohexane, the solution was then transferred into a separating funnel. Ten grams of cyclohexane was used to clean the erlenmeyer flask, and the cleaning liquid was also transferred into the separating funnel.

(2) A 20 g HAc solution ( $1 \mathrm{wt} \%$ ) and $20 \mathrm{~g}$ anhydrous alcohol were placed in a separating funnel, then the separating funnel was shaken vigorously for 3 minutes. Finally the water phase was removed from the bottom of the separating funnel when the oil phase and water phase had separated. The operation was repeated 3 times.
(3) A $20 \mathrm{~g} \mathrm{NaOH}$ solution (1 wt\%) and $20 \mathrm{~g}$ anhydrous alcohol were added to the cyclohexane phase in the separating funnel, and vigorously shaken for 3 minutes, then left it for 1 hour, and the alcohol/water phase collected. The extraction operation was repeated 6 times.

(4) All the alcohol/water phase collected in step 3 was transferred into a clean separating funnel. Then $10 \mathrm{~g}$ cyclohexane was added, and shaken, and then left to stand. Finally the alcohol/water phase in the bottom was collected. The operation was repeated until the cyclohexane phase left no oil mark on a filter paper.

(5) The alcohol/water phase was acidified using $10 \mathrm{wt} \%$ $\mathrm{HNO}_{3}$ solution until the $\mathrm{pH}$ value of the solution decreased to 3 . Then the petroleum acids were extracted by $40 \mathrm{~mL}$ cyclohexane. The operation was repeated 3 times.

(6) Deionized water was used to wash the cyclohexane phase collected in step 5 until the water phase in bottom became neutral ( $\mathrm{pH} 7)$. Then the cyclohexane phase was transferred into a clean erlenmeyer flask, and the cyclohexane solvent was evaporated in a constant temperature oil bath, and finally the petroleum acids were obtained.

\subsection{Analysis and identification of petroleum acids}

The structure of petroleum acids was characterized with a Magna-IR 560 FT-IR using the liquid smear method, and a Micromass Quattro micro API MS with ESI.

\section{Results and Discussion}

\subsection{Properties of Liaohe super-heavy oil}

Table 1 shows that Liaohe super-heavy oil has higher density, viscosity, total acid number (TAN), and higher heteroatom $\mathrm{N}$ and $\mathrm{O}$, ash, and trace metal contents, but lower sulfide content, than conventional crude oil. And from its initial boiling point (IBP) up to $441 \mathrm{~K}$, it is indicated that the super-heavy oil has low content of light fractions. The oxygen content is up to $2.2 \mathrm{wt} \%$, and the TAN is $12.76 \mathrm{mg}(\mathrm{KOH}) / \mathrm{g}$, indicating that the content of petroleum acids was high.

\subsection{Content of petroleum acids}

According to the procedures for separation and extraction of petroleum acids described in section 2.2, two parallel experiments were carried out to obtain a petroleum acid sample from the Liaohe super-heavy oil. The experimental data listed in Table 2 show that the content of petroleum acids was $3 \mathrm{wt} \%$ or more. If all the acid compounds in Liaohe super-heavy oil were converted into petroleum acids, the TAN of the super-heavy oil would be more than $12.76 \mathrm{mg}(\mathrm{KOH}) /$ $\mathrm{g}$. These results indicate that the petroleum acids in the superheavy oil might partly be in the form of organic salts.

Table 2 Experimental data of petroleum acids separated from Liaohe super-heavy oil

\begin{tabular}{ccccc}
\hline No. & $\begin{array}{c}\text { Super-heavy } \\
\text { oil, g }\end{array}$ & $\begin{array}{c}\text { Petroleum acid } \\
\text { g }\end{array}$ & $\begin{array}{c}\text { Content of } \\
\text { petroleum acid, wt } \%\end{array}$ & $\begin{array}{c}\text { Color of petroleum } \\
\text { acid }\end{array}$ \\
\hline 1 & 20.4 & 0.6283 & 3.08 & brown \\
2 & 20.0 & 0.6002 & 3.00 & \\
\hline
\end{tabular}




\subsection{Analysis of petroleum acids by FT-IR}

In order to investigate the structure of petroleum acids, FTIR was used to determine the petroleum acids separated and purified from Liaohe super-heavy oil. The FT-IR spectrogram shown in Fig. 1 shows that the absorption peak with a broad wave number range of 3,300-2,500 $\mathrm{cm}^{-1}$ can be attributed to the stretching vibration of hydroxyl in carboxylic acid, and the absorption peak at $1,707 \mathrm{~cm}^{-1}$ wave number can be attributed to the stretching vibration of carbonyl in carboxylic acid. The absorption peaks at $1,412 \mathrm{~cm}^{-1}$ and $939 \mathrm{~cm}^{-1}$ wave number correspond to the bending vibration of hydroxyl in carboxylic acid. Based on the characteristics of the above absorption spectra bands, it could be easily concluded that the petroleum acid has the structure of a typical monocarboxylic compound, such as an aliphatic acid or naphthenic acid. From the low strength of the absorption peak at $1,611 \mathrm{~cm}^{-1}$ wave number, it is found that the content of carboxylic acid with aromatic rings is very low. The absorption peaks of hydroxyl carboxylic acid and olefine acid do not appear in Fig. 1. Meanwhile, the obvious absorption did not occur in the neighborhood of the $722 \mathrm{~cm}^{-1}$ wave number, indicating that the number of methylenes connected to carboxyl is not more than 4 in a naphthenic acid. Since cyclohexane was used as the extraction solvent, the petroleum acids which were separated from the super-heavy oil exist in the form of naphthenic acid, and they could be expressed by the general formula of $\mathrm{C}_{n} \mathrm{H}_{2 n+Z} \mathrm{O}_{2}$, where $n$ is the number of carbon, $\mathrm{Z}$ denotes the type of homolog, e.g. $Z=0$ meant aliphatic acid, and $Z=-2,-4, \cdots,-12$ meant naphthenic acid with 1-6 rings, respectively. And the naphthenic acids has two kinds of structure, one is that the carboxyl is directly connected with naphthenic ring carbon, and the other is that the carboxyl is connected with naphthenic ring carbon by a chain of less than 4 methylene.

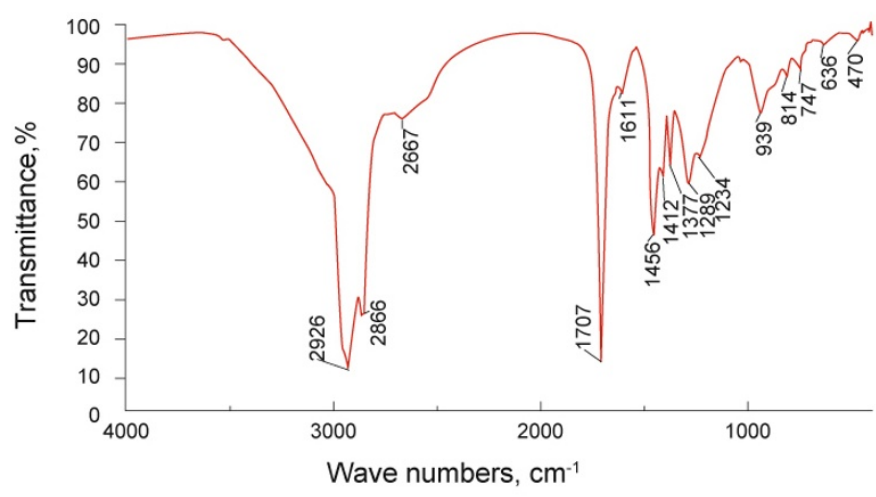

Fig. 1 The FT-IR spectrogram of petroleum acids from the Liaohe super-heavy oil

\subsection{MS characterization of petroleum acids}

Since the composition of petroleum acids from superheavy oil is very complex, standard sample of petroleum acids are difficult to obtain, therefore it was difficult to obtain the accurate structure and quantitative analysis result for relevant petroleum acids.

In order to determine the composition of petroleum acids, mass spectrometry with electrospray ionization (ESI) was used. The advantage of ESI is that the molecules of sample do not crack in it, and thus do not produce ion fragments during analysis, so the every peak in each mass spectrum represents one species of petroleum acid. The related mass spectra are shown in Fig. 2.

Fig. 2 shows that the petroleum acid is a complicated mixture, and its number of carbon is in range of 11-69 with one to six naphthenic rings and/or one to two aromatic rings. The molecular weight of petroleum acids is in the range of 190-1,000. For the highest mass spectra peak, the molecular weight is 307 and the number of carbons is 19 . The number of naphthenic rings and/or aromatic rings in different petroleum acids is also different.

According to the general molecular formula of naphthenic acid and the peak height in mass spectrum, the content of different kinds of petroleum acids could be calculated, and the results are listed in Table 3 .

Table 3 shows that the naphthenic acids are the majority of petroleum acids with a content of about $85 \%$, and there is only $13.60 \%$ aliphatic acid. Among all the petroleum acids, naphthenic acid with 2 rings accounts for about $20 \%$.

Table 3 The content of different kinds of petroleum acids

\begin{tabular}{cc}
\hline Type of petroleum acid & Molar fraction, \% \\
\hline Aliphatic acid & 13.60 \\
Naphthenic acid with 1 ring & 14.73 \\
Naphthenic acid with 2 rings & 19.30 \\
Naphthenic acid with 3 rings & 14.62 \\
Naphthenic acid with 4 rings or Aromatic & 13.41 \\
acid with 1 ring & 12.01 \\
Naphthenic acid with 5 rings or Naphthenic \\
acid with phenyl \\
Naphthenic acid with 6 rings or Naphthenic \\
acid with diphenyl
\end{tabular}

\subsection{Analysis of metal content after acidification of super-heavy oil}

When the Liaohe super-heavy oil was acidified by $1 \mathrm{wt} \%$ HAc, the metal content was analyzed by Vista AX ICP-AES, and the calcium, nickel and iron contents in the super-heavy oil sample with and without acidification processing are compared (Table 4). Table 4 shows that $99.2 \%$ of calcium and $11.2 \%$ of iron were removed from the super-heavy oil sample, but the nickel content was hardly changed by acidification. The results demonstrate that the calcium compounds in superheavy oil are easily decomposed by using $1 \mathrm{wt} \%$ HAc, but only minority of iron compounds could be decomposed, and the nickel compounds are hardly decomposed. Therefore it could be concluded that the existing forms of calcium, nickel and iron in the super-heavy oil is different. From our previous work (Wu et al, 2006) it was known that the watersoluble inorganic calcium in Liaohe super-heavy oil was 


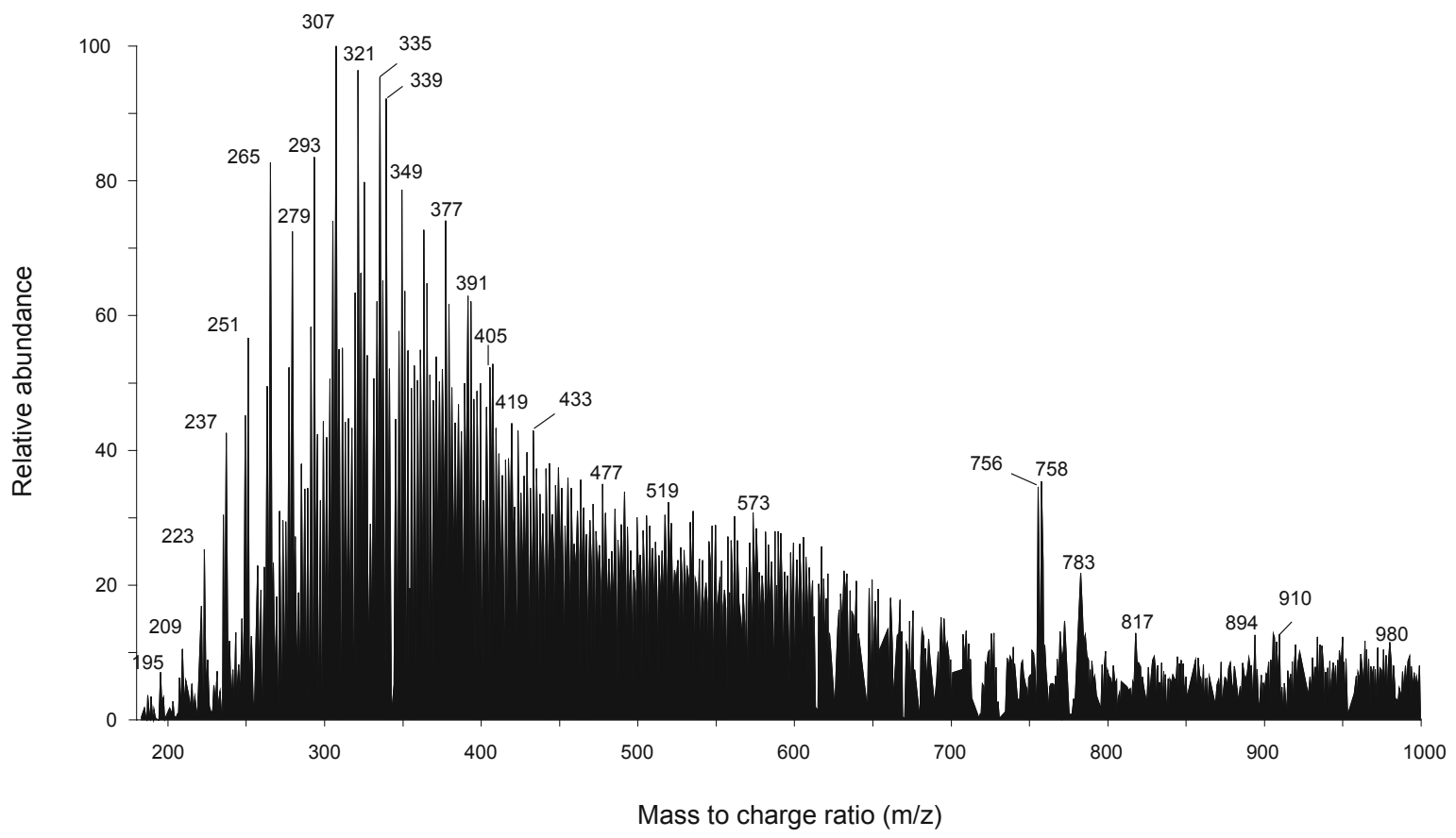

Fig. 2 The MS spectrum for petroleum acids from the Liaohe super-heavy oil

$12.4 \%$, therefore more than $80 \%$ calcium would exist in the form of metal salts of petroleum acid. Since the $1 \mathrm{wt} \%$ HAc acidification processing could only remove the trace metals exist in the form of inorganic salts and metal salts of petroleum acid, therefore the majority of inorganic salts and metal salts of petroleum acid could be removed from superheavy oil by an acidic demetallization agent. Based on the above analyses, it could be concluded that both petroleum acids and their metal salts coexist in the super-heavy oil.

Table 4 Comparison of metal content in Liaohe super-heavy oil before and after acidification

\begin{tabular}{cccccccc}
\hline \multirow{2}{*}{ Samples of super-heavy oil } & \multicolumn{3}{c}{ Metal content, $\mu \mathrm{g} \cdot \mathrm{g}^{-1}$} & \multicolumn{3}{c}{ Metal content, \% } \\
& $\mathrm{Ca}$ & $\mathrm{Ni}$ & $\mathrm{Fe}$ & $\mathrm{Ca}$ & $\mathrm{Ni}$ & $\mathrm{Fe}$ \\
\hline With acidification processing & 524 & 125 & 47.5 & 100 & 100 & 100 \\
Without acidification processing & 4.4 & 124 & 42.2 & 0.8 & 99.2 & 88.8 \\
\hline
\end{tabular}

\section{Conclusions}

1) The petroleum acids can be effectively separated from super-heavy oil by solvent extraction. The experimental results demonstrated that the content of petroleum acids in Liaohe super-heavy oil is about $3 \mathrm{wt} \%$.

2) The petroleum acids in Liaohe super-heavy oil are basically monocarboxylic acids, and they are a mixture of aliphatic acids and naphthenic acids.

3) The molecular weight of petroleum acids in superheavy oil is in the range of 190-1000, and their carbon number distributes in the range of 11-69.

4) The majority of petroleum acids in the super-heavy oil are naphthenic acids. Among the naphthenic acids, naphthenic acids with 2 rings are the most common and their content account for about $20 \%$ of the total petroleum acids. There exist two kinds of naphthenic acid structure, one is the carboxyl directly connected with naphthenic ring, and the other is the carboxyl connected with naphthenic ring via a chain of less than 4 methylene.

5) The petroleum acids in Liaohe super-heavy oil partly exist in the form of acid and partly in the form of metal salts of petroleum acids.

\section{Acknowledgement}

Authors would like to thank the National Natural Science Foundation of China (Grant No. 20576075) and the PetroChina Company for the financial support to this work, and thank Dr. Liu Zelong, Dr. Huang Shaokai of RIPP, and Dr. Chen Yu of CUP for their help in the sample analysis.

\section{References}

Barrow M P, McDonnell L A, Feng X, et al. Determination of the nature of naphthenic acids present in crude oils using nanospray Fourier Transform ion cyclotron resonance mass spectrometry: the continued battle against corrosion. Analytical Chemistry. 2003. 75(4): 860-866

Blum S C, Olmstead N and Bearden R. Thermal decomposition of naphthenic acids. 1998. US Patent: 5820750

Dzidic I, Somerville A C, Raia J C, et al. Determination of naphthenic acids in California crudes and refinery wastewaters by fluoride ion chemical ionization mass spectrometry. Analytical Chemistry. 1988. 60(13): 1318-1323

Fu X Q, Tian S B, Hou S D, et al. Study on the structure and composition of petroleum acids in the Penglai and Sudan high acid crude oil. Chemical Engineering of Oil \& Gas. 2007. 36(6): 507-510 (in Chinese) 
Gabryelski W and Froese K L. Characterization of naphthenic acids by electrospray ionization high-field asymmetric waveform ion mobility spectrometry mass spectrometry. Analytical Chemistry. 2003. 75(17): 4612-4623

Gaikar V G and Maiti D. Adsorptive recovery of naphthenic acids using ion-exchange resins. Reactive \& Functional Polymers. 1996. 31 : $155-164$

Gallegos E J. Gas chromatography/fast-atom bombardment mass spectrometry of carboxylic acids. Journal of Chromatographic Science. 1987. 25(7): 296-301

Grande K and Sorlie C. Process for removing essentially naphthenic acids from a hydrocarbon oil. 2000. US Patent: 6063266

Hsu C S, Dechert G J, Robbins W K, et al. Naphthenic acids in crude oils characterized by mass spectrometry. Energy \& Fuels. 2000. 14(1): 217-223

Huang S K, Tian S B, Liu Z L, et al. Determination of the structure and composition of petroleum acids in the diesel fractions of crude oil with high acid number. Petroleum Processing and Petrochemicals. 2007. 38(4): 51-55 (in Chinese)

Hughey C A, Galasso S A, Zumberge J E. Detailed compositional comparison of acidic NSO compounds in biodegraded reservoir and surface crude oils by negative ion electrospray Fourier transform ion cyclotron resonance mass spectrometry. Fuel. 2007. 86(5-6): 758768

John W P, Rughani J, Green S A, et al. Analysis and characterization of naphthenic acids by gas chromatography-electron impact mass spectrometry of tert.-butyldimethylsilyl derivatives. Journal of Chromatography A. 1998. 807(2): 241-251

Qian K, Robbins W K, Hughey C A, et al. Resolution and identification of elemental compositions for more than 3000 crude acids in heavy petroleum by negative-ion microelectrospray high-field Fourier transform ion cyclotron resonance mass spectrometry. Energy \& Fuels. 2001. 15(6): 1505-1511

Varadaraj R and David W S. Process for neutralization of petroleum acids (LAW810). 2000. US Patent: 6030523

Wu B C, Zhu J H, Wang J, et al. Technique for high-viscosity crude oil demetallization in the Liaohe oil field. Energy \& Fuels. 2006. 19(4): 1345-1349

(Edited by Zhu Xiuqin) 